\title{
Dielectric and electrical properties of $\mathrm{Na}_{2} \mathrm{~Pb}_{2} \mathrm{La}_{2} \mathrm{~W}_{2} \mathrm{Ti}_{4} \mathrm{Ta}_{4} \mathrm{O}_{30}$ electroceramics
}

\author{
P. R. DAS ${ }^{a, *}$, S. BEHERA ${ }^{b}$, R. PADHEE ${ }^{a}$, P. NAYAK ${ }^{c}$, R.N.P. CHOUDHARY ${ }^{a}$ \\ ${ }^{a}$ Department of Physics, Institute of Technical Education \& Research, \\ Siksha 'O' Anusandhan University, Bhubaneswar-751030, Odisha, India; \\ ${ }^{b}$ Department of Physics, Hi-tech College Engineering, Bhubaneswar- 75102, Odisha, India; \\ ${ }^{c}$ School of Physics, Sambalpur University, Jyoti Vihar, Burla -768019, Odisha, India
}

Received August 23, 2012; Accepted October 6, 2012

(C) The Author(s) 2012. This article is published with open access at Springerlink.com

\begin{abstract}
The polycrystalline sample of complex tungsten-bronze type compound $\left(\mathrm{Na}_{2} \mathrm{~Pb}_{2} \mathrm{La}_{2} \mathrm{~W}_{2} \mathrm{Ti}_{4} \mathrm{Ta}_{4} \mathrm{O}_{30}\right)$ was prepared by a high-temperature solid-state reaction technique. Room temperature preliminary structural study using X-ray diffraction (XRD) data exhibits the formation of a single-phase new compound. The SEM micrograph of the compound exhibits non uniform rectangular grains distributed throughout the sample surface. Detailed studies of dielectric parameters $\left(\varepsilon_{\mathrm{r}}, \tan \delta\right)$ as a function of temperature and frequency, and P-E hysteresis (spontaneous polarization) confirmed the existence of ferroelectricity in the material. Complex impedance spectroscopy analysis, carried out as a function of frequency at different temperatures, established a correlation between the microstructure and electrical properties of the material. The electrical relaxation process occurring in the material is temperature dependent. The activation energy found from the Arrhenius plot that the conduction process in the material is of mixed type. The nature of frequency dependence of ac conductivity suggests that the material obeys Jonscher's universal power law.
\end{abstract}

Key words: electronic material; ferroelectricity; XRD; electrical conductivity

\section{Introduction}

Tungsten-bronze (TB) compounds belong to an important class of dielectric materials, which display interesting ferroelectric, pyroelectric, piezoelectric and nonlinear optic behaviors [1-3]. Since the discovery of ferroelectricity in lead meta- niobate $[4,5]$ and lead

\footnotetext{
* Corresponding author.

E-mail:prdas63@gmail.com
}

meta tantalate [6], there has been rapid progress in search of new TB-type materials, required for various electronic devices such as multi-layer capacitors, transducers, actuators, random access memory, microwave dielectric resonators, phase shifters, pyroelectric detectors, etc because of their relatively high dielectric constant and low dielectric loss [7-11]. Detailed literature survey on TB structure ferroelectrics (single crystal, ceramics and thin films) reveals that a lot of work has already been done on ferroelectric ceramics of this family of different chemical formula. Recent studies on some complex compounds of the 
family such as $\mathrm{Na}_{2} \mathrm{~Pb}_{2} \mathrm{Pr}_{2} \mathrm{~W}_{2} \mathrm{Ti}_{4} \mathrm{Nb}_{4} \mathrm{O}_{30}$ [12], $\mathrm{Na}_{2} \mathrm{~Pb}_{2} \mathrm{Nd}_{2} \mathrm{~W}_{2} \mathrm{Ti}_{4} \mathrm{Ta}_{4} \mathrm{O}_{30}$ [13], $\mathrm{Na}_{2} \mathrm{~Pb}_{2} \mathrm{Sm}_{2} \mathrm{~W}_{2} \mathrm{Ti}_{4} \mathrm{Ta}_{4} \mathrm{O}_{30}$ [14], $\quad \mathrm{K}_{2} \mathrm{Ba}_{2} \mathrm{Nd}_{2} \mathrm{Ti}_{4} \mathrm{Nb}_{4} \mathrm{~W}_{2} \mathrm{O}_{30} \quad$ [15], $\mathrm{Li}_{2} \mathrm{~Pb}_{2} \mathrm{Pr}_{2} \mathrm{~W}_{2} \mathrm{Ti}_{4} \mathrm{Nb}_{4} \mathrm{O}_{30} \quad[16], \quad \mathrm{Na}_{2} \mathrm{~Pb}_{2} \mathrm{R}_{2} \mathrm{~W}_{2} \mathrm{Ti}_{4} \mathrm{~V}_{4} \mathrm{O}_{30}$ $\left(\begin{array}{llll}R=G d, & E u\end{array}\right) \quad[17], \quad \mathrm{Li}_{2} \mathrm{~Pb}_{2} \mathrm{La}_{2} \mathrm{~W}_{2} \mathrm{Ti}_{4} \mathrm{Nb}_{4} \mathrm{O}_{30} \quad$ [18] ceramics showed the presence of diffuse phase transition in these TB ferroelectrics. TB structural family have a general formula $\left[\left(\mathrm{A}_{1}\right)_{2}\left(\mathrm{~A}_{2}\right)_{4}(\mathrm{C})_{4}\right]\left[\left(\mathrm{B}_{1}\right)_{2}\left(\mathrm{~B}_{2}\right)_{8}\right] \mathrm{O}_{30}$, where the $\mathrm{A}$ site is usually occupied by mono to trivalent cations and $\mathrm{B}$ sites by $\mathrm{W}^{+6}, \mathrm{Ti}^{+4}, \mathrm{Nb}^{+5}, \mathrm{Ta}^{+5}$ or $\mathrm{V}^{+5}$ ions. This complex formula can be simplified to $\mathrm{A}_{6} \mathrm{~B}_{10} \mathrm{O}_{30}[19,20]$ by suitably selected ions at appropriate sites. The distributions of metal cations in different interstices can improve physical properties such as electro-optic, nonlinear optic, elasto-optic, ferroelectricity and pyro-electricity in these materials. Further, structural flexibility and chemical versatility of the materials make them more suitable for device applications [21]. Some electrical properties of TB structure compounds exist due to the contributions of various components and process such as intra-grain, inter-grain and electrode/interface process. In addition to the above, some complex TB compounds are more attractive because of their relatively low dielectric constant, high pyroelectric coefficient/figure of merit and low loss, and hence they are useful for devices. Though a lot of work has been done on TB compounds [22-27], not much work on dielectric and impedance properties have been reported so far on complex TB structured compounds having all the valence elements (I-VI). In view of the above importance and unavailability of experimental data on the complex systems we have synthesized and characterized such type of many materials. In this paper we report structural, dielectric and electrical properties of $\mathrm{Na}_{2} \mathrm{~Pb}_{2} \mathrm{La}_{2} \mathrm{~W}_{2} \mathrm{Ti}_{4} \mathrm{Ta}_{4} \mathrm{O}_{30}$

\section{Experimental}

The polycrystalline sample of $\mathrm{Na}_{2} \mathrm{~Pb}_{2} \mathrm{La}_{2} \mathrm{~W}_{2} \mathrm{Ti}_{4} \mathrm{Ta}_{4} \mathrm{O}_{30}$ (abbreviated as NLaT) was prepared by a high-temperature solid-state reaction technique using high purity (AR grade) raw materials: $\mathrm{Na}_{2} \mathrm{CO}_{3}(99 \%$, $\mathrm{M} / \mathrm{s}$ s.d. Fine chem. Ltd.), $\mathrm{PbO}$ (99.9\%, E. Merck Ltd., India), $\mathrm{TiO}_{2}, \mathrm{WO}_{3}, \mathrm{Ta}_{2} \mathrm{O}_{5}(99 \%$, M/s Loba Chemie Pvt. Ltd., India), and $\mathrm{La}_{2} \mathrm{O}_{3}(99.9 \%$, Indian Rare Earth Ltd., India) in suitable stoichiometric proportion. The ingredients were thoroughly mixed and grinded in dry (air) and wet (methanol) medium for $1 \mathrm{~h}$ each in an agate mortar and pestle. Initial firing or calcination of the mixed material was carried out in a high-purity alumina crucible at $1100{ }^{\circ} \mathrm{C}$ (decided by repeated firing) for $4 \mathrm{~h}$ in an air atmosphere. The process of grinding and calcination was repeated several times to complete the reaction for the formation of the compound. To check the formation of the compound, X-ray diffraction data/pattern were recorded over a wide range of Bragg's angle $(2 \theta)\left(20^{\circ} \leqslant 2 \theta \leqslant 80^{\circ}\right)$ at a scanning rate of $3 \mathrm{deg} / \mathrm{min}$ (on calcined powder) at room temperature using an X-ray powder diffractometer (Rigaku Miniflex, Japan) with $\mathrm{Cuk}_{\alpha}$ radiation $(\lambda=1.5405 \AA)$. The fine and homogeneous powder of the compound was mixed with polyvinyl alcohol as binder, and compacted into cylindrical pellets by applying an uni-axial pressure of $4.5 \times$ $10^{6} \mathrm{Nm}^{-2}$ using a hydraulic press. The pellets were sintered at an optimized temperature of $1150{ }^{\circ} \mathrm{C}$ for $4 \mathrm{~h}$. The sintered pellets were polished, coated with high-quality silver paste, and dried at $160{ }^{\circ} \mathrm{C}$ for $10 \mathrm{~h}$ in order to remove moisture (if any) and then cooled to room temperature, before taking any electrical measurements. The unpolished flat surface of the pellet was gold-coated by a sputtering technique to record the surface morphology by scanning electron microscope (SEM, JEOL JSM-5800). The electrical measurements of the silvered- pellet was carried out using a computer-controlled Hioki 3532 LCR Hitester in the frequency range of $10^{2}-10^{6} \mathrm{~Hz}$ at different temperatures $\left(29-500{ }^{\circ} \mathrm{C}\right)$ with a laboratory-designed sample holder and vertical pit furnace. The polarization (hysteresis loop) of the material on the poled sample (6 $\mathrm{kV} / \mathrm{cm}$ at $80{ }^{\circ} \mathrm{C}$ for $10 \mathrm{~h}$ ) was obtained at room as well as other temperatures using P-E loop tracer $(\mathrm{M} / \mathrm{S}$ Marine India, New Delhi).

\section{Result and discussion}

\subsection{Structure/microstructure}

The XRD pattern (Fig. 1) of the compound shows sharp and distinct peaks, which are different from that of the ingredients, suggesting the formation of a new single phase compound. The diffraction peaks of the compound were indexed in different crystal systems and unit cell configurations using a standard computer program package POWD [28]. An orthorhombic unit cell was finally selected on the basis of the best agreement between observed (obs) and calculated (cal) 


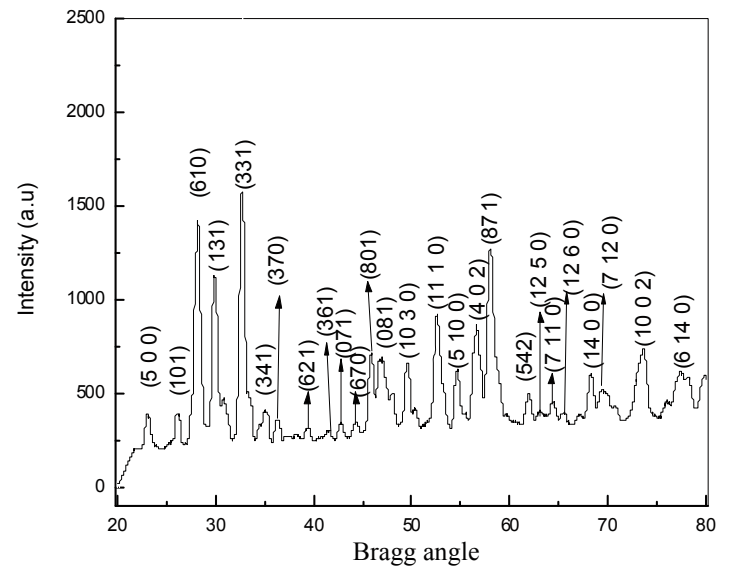

Fig. 1 Indexed X-ray diffraction pattern of NLaT at room temperature.

inter-planar spacing d (i.e., $\sum \Delta d=\sum\left(d_{\text {obs }}-d_{\text {cal }}\right)=$ minimum). The lattice parameters of the selected unit cell were refined using the least-squares sub-routine of POWD, The refined lattice parameters are: $a=$ 19.2384(14) $\AA, \quad b=18.6641(14) \AA, \quad c=3.4619(14) \AA$, Volume $=1243.0556(\AA)^{3}$ (estimated standard deviation in parenthesis). The unit cell parameters and crystal system of the compound are very much consistent with those reported earlier [14]. The orthorhombic distortion calculated as, $\delta=(b-a) /(b+a)$, is found to be 0.0151 , well within the acceptable limits. The TB structure is built on five crystallographic sites. It is difficult to precisely determine the $\mathrm{R}^{+3}$ ions coordination (12- or 15- fold coordination) based on the current results. However, the previous structural studies show that the rare earth cations predominantly prefer the A site $[6,18]$.

Figure 2 shows the SEM micrograph of the sintered pellet recorded at room temperature. The micrograph shows polycrystalline texture of the material. As the

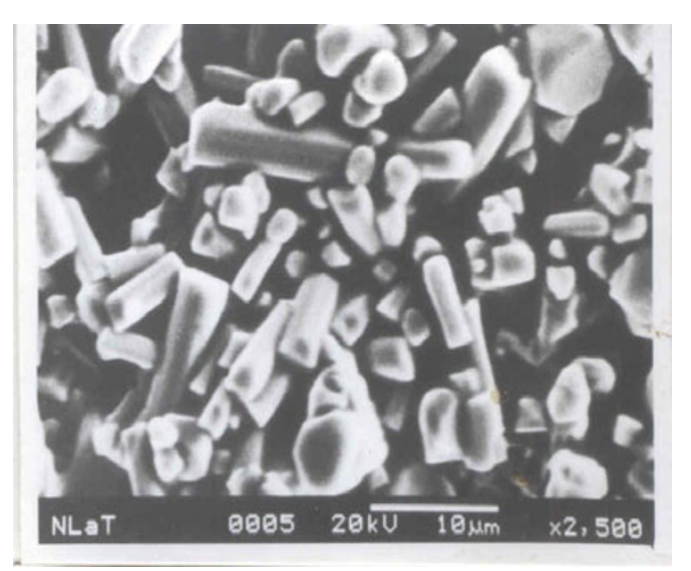

Fig. 2 SEM micrograph of NLaT. rod- and plate -like grains are uniformly distributed (with some voids) over the entire surface, density of the sample can be considered reasonably high for this type of materials. This conclusion is consistent with density determined by physical method (i.e., $>90 \%$ of the theoretical density). The average grain size is found to be in the range $3-13 \mu \mathrm{m}$.

\subsection{Dielectric study}

The temperature-frequency dependence of dielectric constant and tangent loss is shown in Fig. 3. It is observed that both $\varepsilon_{\mathrm{r}}$ and $\tan \delta$ decrease with increase in frequency, which is a general feature of polar dielectrics [29]. As the compound has a dielectric anomaly at $342 \mathrm{~K}$, existence of ferroelectric to paraelectric phase transition in the compound may be considered. The broadened dielectric peak observed in the compound suggests the phase transition of diffused- type. It is also observed this transition temperature $\left(T_{\mathrm{c}}\right)$ is frequency independent, and thus can be classified as a non-relaxor ferroelectrics. The maximum value of dielectric constant $\left(\varepsilon_{\max }\right)$ at $T_{\mathrm{c}}$ for $10 \mathrm{kHz}, 100 \mathrm{kHz}$ and $1 \mathrm{MHz}$ is 316,196 and 143 respectively, which are higher than those of reported ones [13]. Similarly, an anomaly was observed in $\tan \delta$ at $343 \mathrm{~K}$, which is analogous with the anomaly observed in some TB type of compounds [30]. The increasing value of $\tan \delta$ at high temperature region may be considered due to the existence of space charge polarization and reduction of ferroelectric domain wall contribution [14]. The maximum value of $\tan \delta$ at $T_{\mathrm{c}}$ is found to be 2.25, 0.63 and 0.21 at $10,100 \mathrm{kHz}$ and $1 \mathrm{MHz}$ respectively. As the material has diffused phase transition, it is required to estimate the degree of disorder. The calculated value of the degree of disorder or diffusivity $(\gamma)$ using the empirical relation: $\ln \left(\frac{1}{\varepsilon_{r}}-\frac{1}{\varepsilon_{\max }}\right)=\ln K+g \ln \left(T-T_{c}\right) \quad$ [31], with constant $K$, is found to be 1.79 at $10 \mathrm{kHz}$ (Fig. 4), which supports higher degree of disordering in the system [32]. The diffused phase transition in TB compounds may be considered due to randomness of atoms distribution and in-homogeneity. It is known that TB structured compounds lose oxygen during high temperature sintering $[33,34]$ which, follows the Kroger and Vink relation: $\mathrm{Oo} \rightarrow 1 / 2 \mathrm{O}_{2} \uparrow+\mathrm{Vo}+2 \mathrm{e}^{-}$, where Vo denotes oxygen vacancy [35]. Some oxygen vacancies created during high temperature processing induce disordering in the system [36]. As a result 


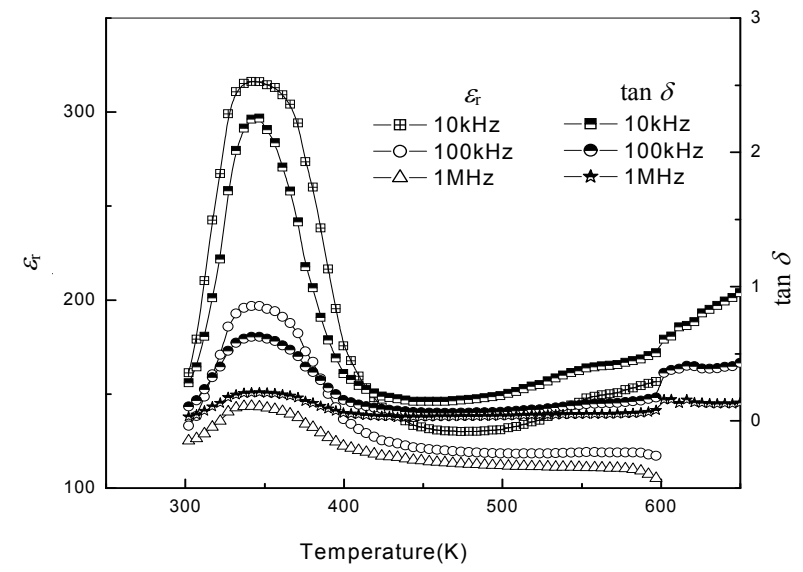

Fig. 3 Variation of $\varepsilon_{\mathrm{r}}$ and $\tan \delta$ of NLaT as a function of temperature at $10 \mathrm{kHz}, 100 \mathrm{kHz}$ and $1 \mathrm{MHz}$ respectively.

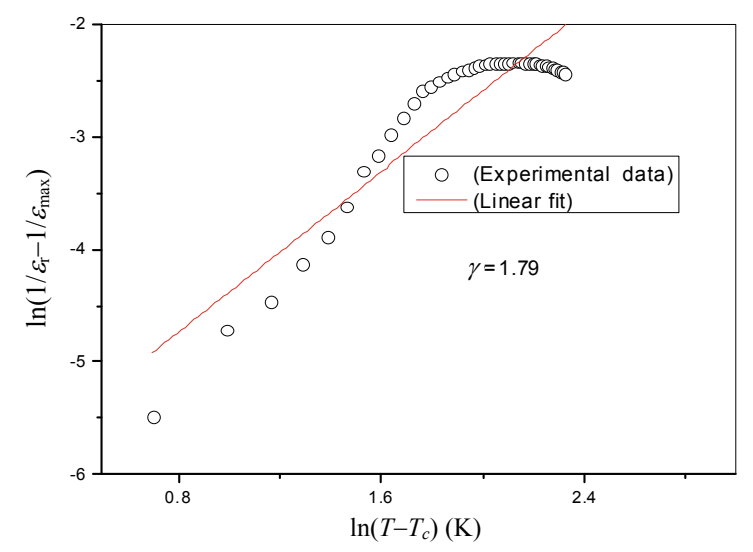

Fig. 4 Variation of $\ln \left(1 / \varepsilon_{r}-1 / \varepsilon_{\max }\right)$ with $\ln \left(T-T_{c}\right)$ at $10 \mathrm{kHz}$ of NLaT.

diffuse type of ferroelectric to paraelectric phase transition occurs. As the value of $\gamma$ is between 1 and 2 ( $\gamma=1$ obeying the Curie Weiss law and $\gamma=2$ for completely disordered system), confirms the diffuse-phase transition in the compound.

\subsection{Polarization study}

Figure 5 shows the polarization - electric field (PE) hysteresis loop of the compound. The remnant polarization (2Pr) and coercive field (Ec) of the compound at $30{ }^{\circ} \mathrm{C}$ were found to be $1.01 \mu \mathrm{C} / \mathrm{cm}^{2}$ and $0.1423 \mathrm{kV} / \mathrm{cm}$, respectively. The appearance of hysteresis loop confirms the ferroelectric properties at room temperature.

\subsection{Electrical properties}

\subsubsection{Impedance study}

The complex impedance spectroscopy (CIS) [37] is

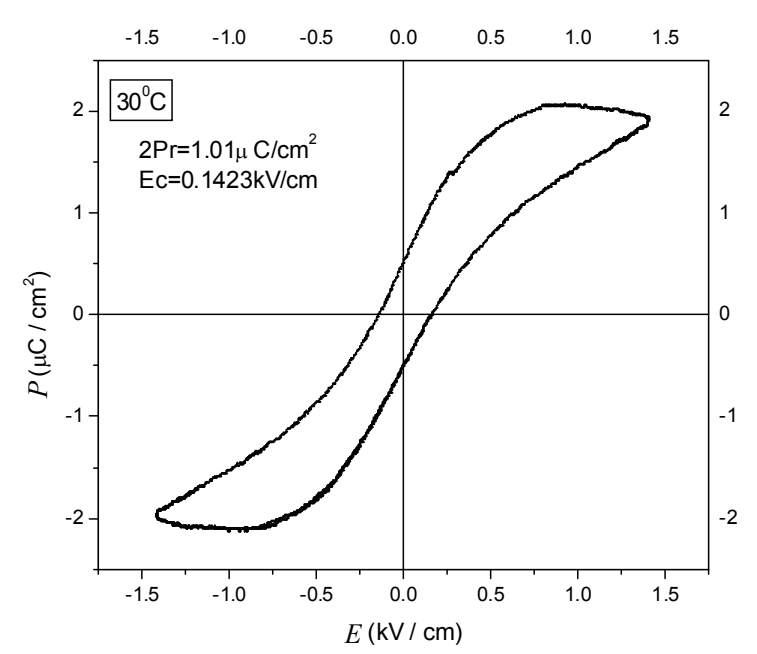

Fig. 5 Hysteresis loop of NLaT.

used to analyze the electrical response (i.e., transport properties) of polycrystalline materials (ferroelectric, ionic conductor, etc) in a wide range of frequencies. This technique separates the contributions of (i) bulk, (ii) grain boundary and (iii) electrode polarization in complex impedance and other related electrical parameters with different equivalent circuits. The impedance parameters of the materials give us data having both real (resistive) and imaginary (reactive) components. The following basic equations of impedance, electrical modulus and related parameters are normally used in this technique: complex impedance, $Z(\omega)=Z^{\prime}-j Z^{\prime \prime}=R_{s}-\frac{j}{\omega C_{s}}$, complex modulus, $M(\omega)=\frac{1}{\varepsilon(\omega)}=M^{\prime}+j M^{\prime \prime}=j \omega C o Z$, complex admittance $Y^{*}=Y^{\prime}+j Y^{\prime \prime}=j \omega C_{o} \varepsilon^{*}=\left(R_{P}\right)^{-1}+j \omega C_{p}$ and complex permittivity $\varepsilon^{*}=\varepsilon^{\prime}-j \varepsilon^{\prime \prime}$, where $\omega=2 \pi f$ is the angular frequency; $C_{0}$ is the geometrical capacitance, $j=\sqrt{-1}$. The subscripts $\mathrm{p}$ and $\mathrm{s}$ refer to the equivalent parallel and series circuit components respectively. The complex impedance of a cell configuration of electrode/ceramic/electrode can be explained in terms of the sum of the RC circuits in parallel combination mode.

Figure 6a shows the variation of $Z^{\prime}$ and $Z^{\prime \prime}$ with frequency at different temperatures. The value of $Z^{\prime}$ decreases with the rise in both frequency and temperature which is related to the electrical conductivity of the material. At higher frequency the value of $Z^{\prime}$ (for selected temperatures) coincides with each other suggesting the release of space charges. 


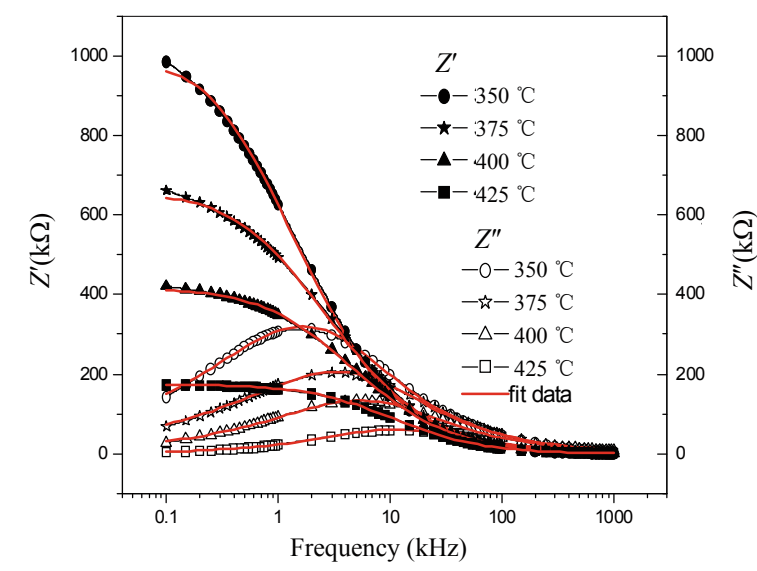

(a) Variation of $Z^{\prime}$ and $Z^{\prime \prime}$ with frequency at selected temperatures

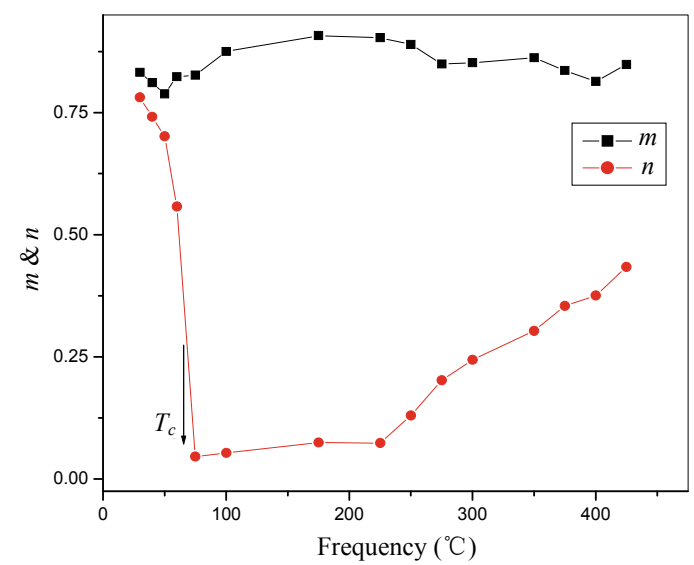

(b) variation of fitting parameters $(m \& n)$ with temperature

Fig. 6

The decrease in the value of $Z^{\prime}$ with temperature suggest the NTCR behaviour of the material. The $Z^{\prime \prime}$ attains a maximum value at a particular frequency, known as electrical relaxation frequency $\left(\omega_{\max }\right)$ and then decreases. The appearance of peaks in the loss spectrum exhibits the existence of relaxation properties in the material. The broadening of peaks on increasing temperature confirms the existence of (i) temperature dependence of relaxation process and (ii) diffused phase transition phenomena in the material [38]. The relaxation species may be electrons in low temperature region whereas defects/vacancies in higher temperature region may be responsible for electrical conduction in the material [39]. In the imaginary plot of the impedance, the high frequency slope is independent of temperature. On the other hand, low frequency slope is strongly temperature dependent. The temperature dependent slope clearly suggests that there are two distinct dispersion mechanism involved in the sample. The asymmetric nature of the plot $[40,41]$ can be explained using the equivalent circuits: $\mathrm{CQR}$ for low temperature and (CQR) (CR) for high temperature (Fig. 7, inset). Jonscher's universal capacitances can be expressed as, $C=A(\mathrm{j} \omega)^{m-1}$ and $Q=A(\mathrm{j} \omega)^{n-1}$ [42]. The frequency dependence of the complex impedance can be expressed as $Z^{*}=\frac{R_{o}}{1+\left(\frac{j \omega}{\omega_{1}}\right)^{m}+\left(\frac{j \omega}{\omega_{2}}\right)^{n}}$ [41] where $\omega_{1}\left(=2 \pi f_{1}\right)$ and $\omega_{2}\left(=2 \pi f_{2}\right)$ are the first and second characteristic angular frequencies respectively, exponent $m$ is for high frequency and $n$ is for low frequency. An excellent agreement between experimental and calculated values for both real and imaginary parts of impedance is obtained from non-linear fitting curve (Fig. 6a) using the formula $Z^{\mathrm{II}}=\frac{R_{o}}{\left(\frac{\omega}{\omega_{1}}\right)^{m}+\left(\frac{\omega}{\omega_{2}}\right)^{-n}}$ [41].

The variation of fitting parameters $(m$ and $n)$ with temperature is shown in Fig. 6b. It is seen that $m$ is close to unity and temperature independent. On the other hand the value of $\mathrm{n}$ is much less than one, and is temperature dependent. The value of $n$ first decreases with rise in temperature and then attains minimum near $T_{\mathrm{c}}$. Again it increases slowly. The minimum value of $n$ near $T_{\mathrm{c}}$ can be explained by considering the restoring force between charge carriers and lattice [41]. The above variation in the value of $n$ can be explained by the theory given by Dissado and Hill $[43,44]$. According to their theory, the exponent $n$ characterizes the magnitude of the correlation in a single dipole reorientation. The unit value of $n$ corresponds to fully correlated transitions, and zero corresponds to fully uncorrelated transition. In our experiment $\mathrm{n}$ tends to a minimum value near $T_{\mathrm{c}}$ suggesting a strongly uncorrelated reorientation of the charge carrier polarization at transition points. These results and conclusion are very much consistent with those reported earlier [30].

Figures $7 \mathrm{a}, 7 \mathrm{~b}$ show the Nyquist- plots $\left(Z^{\prime}\right.$ versus $\left.Z^{\prime \prime}\right)$ with experimental and fitted data using ZSWIMPWIN ver. 2 [45] of NLaT at selected temperatures. This plot has one semicircular arc in the low temperature region $\left(200-350{ }^{\circ} \mathrm{C}\right)$ whereas at higher 


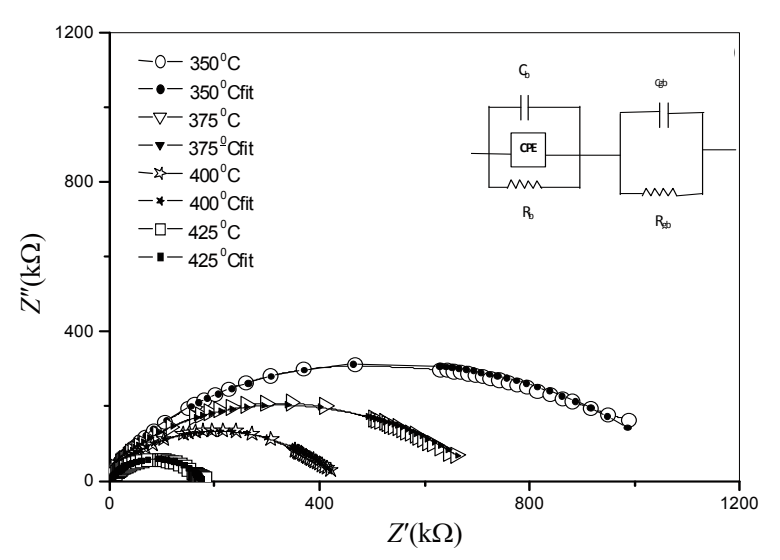

(a)

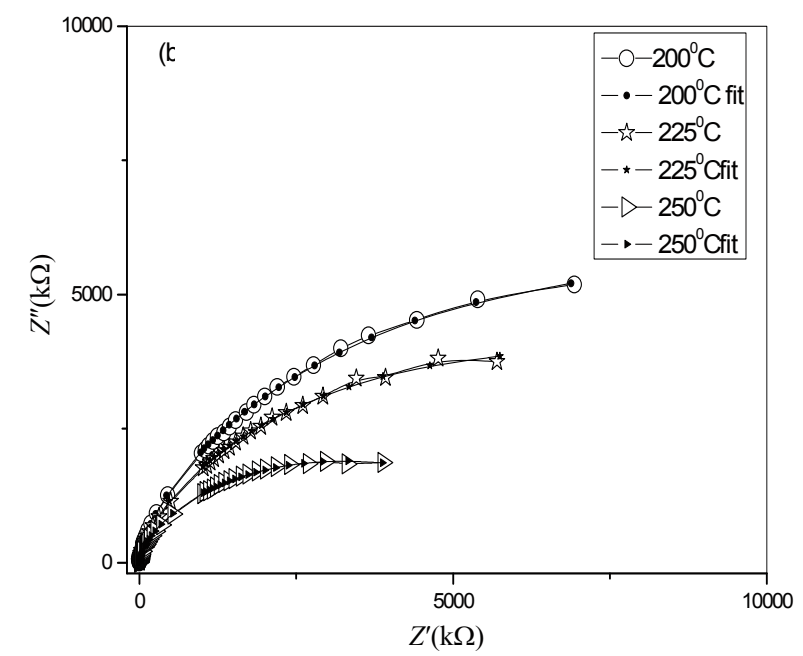

Fig. 7 Variation of $Z^{\prime \prime}$ with $Z^{\prime}$ at different temperatures.

temperatures $\left(375-425^{\circ} \mathrm{C}\right)$ two semicircular arcs (with centre below the real axis) are observed. This indicates that transport properties of the material are mainly due to the bulk (intragrain) at low temperature, and due to bulk and grain boundary at higher temperatures [46]. Most widely accepted approach to interpret the depression of semicircles is statistical distribution of relaxation time (non-Debye type of relaxation) in the material [47]. The equivalent circuit consists of parallel combination of (CQR) and (CR), where $Q$ is known as constant phase element (CPE). The admittance (Y) of $\mathrm{CPE}$ is expressed as: $Y(\mathrm{CPE})=A_{0}(\mathrm{j} \omega)^{n}=A \omega^{n}+\mathrm{j} B \omega^{n}$, where $A=A_{0} \cos (n \pi / 2)$ and $B=A_{0} \sin (n \pi / 2)$. The values of $A_{0}$ and $n$ are frequency independent but temperature dependent. $A_{0}$ is the magnitude of the dispersion, and $0 \leqslant n \leqslant 1$. For an ideal capacitor $n=1$ and for ideal resistor $n=0$ [48]. Further, the non-coincidence of $Z^{\prime \prime}$ spectra with frequency in all the temperature range confirms the departure from ideal Debye type [49], and hence justify the presence of constant phase element (CPE). This behavior follows the Jonscher's universal power law. Therefore a constant phase element (CPE) can be introduced in the equivalent circuit. It shows the power law dependence of the impedance over several decades of frequency domain [50]. As the temperature increases, the intercept of the semicircles at the $Z^{\prime}$-axis shifts towards lower $Z^{\prime}$ values suggesting the reduction of the grain (bulk) resistance. This confirms the negative temperature co-efficient of resistance (NTCR) behavior of the material. Further, the depressed semicircles have their centers below the real axis, which again indicates the departure from the ideal Debye-type behavior [37]. Above observations suggest that there is a distribution of relaxation time instead of a single relaxation time in the material [30].

The variation of relaxation time $(\tau)$ with reciprocal of temperature $\left(10^{3} / T\right)$ is shown in Fig. 8. This graph follows the Arrhenius relation, $\tau=\tau_{\mathrm{o}} \exp \left(-E_{\mathrm{a}} / K_{\mathrm{B}} T\right)$ where the symbols have their usual meanings. The relaxation time $(\tau)$ was calculated from $Z^{\prime \prime}$ versus frequency plot using the relation $\tau=1 / \omega=1 / 2 \pi f_{\max }$, where $f_{\max }$ is the relaxation frequency. It is observed that the value of $\tau$ decreases with an increase in temperature like- semiconductor. The value of activation energy $\left(E_{\mathrm{a}}\right)$ was found to be $0.92 \mathrm{eV}$ which agrees well with that of a semiconductor.

\subsection{2 de conductivity}

Figure 9 shows the variation of dc conductivity with respect to inverse of absolute temperature. The value of bulk conductivity of the material was evaluated from the complex impedance plots of the sample at different temperatures using the relation: $\sigma_{\mathrm{dc}}=t / R_{\mathrm{b}} A$, where $R_{\mathrm{b}}$ is the bulk resistance, $\mathrm{t}$ the thickness and $A$ is the surface area of the sample. It is found that the $\mathrm{dc}$

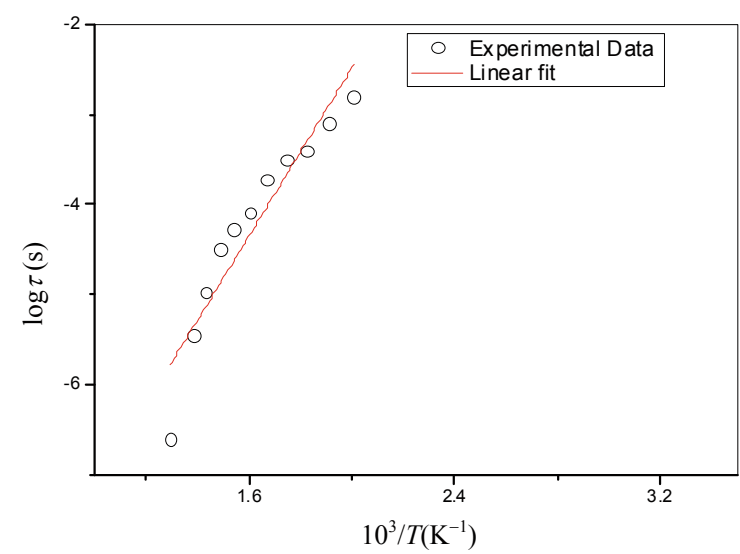

Fig. 8 Variation of relaxation time $(\tau)$ as a function of reciprocal of absolute temperature. 


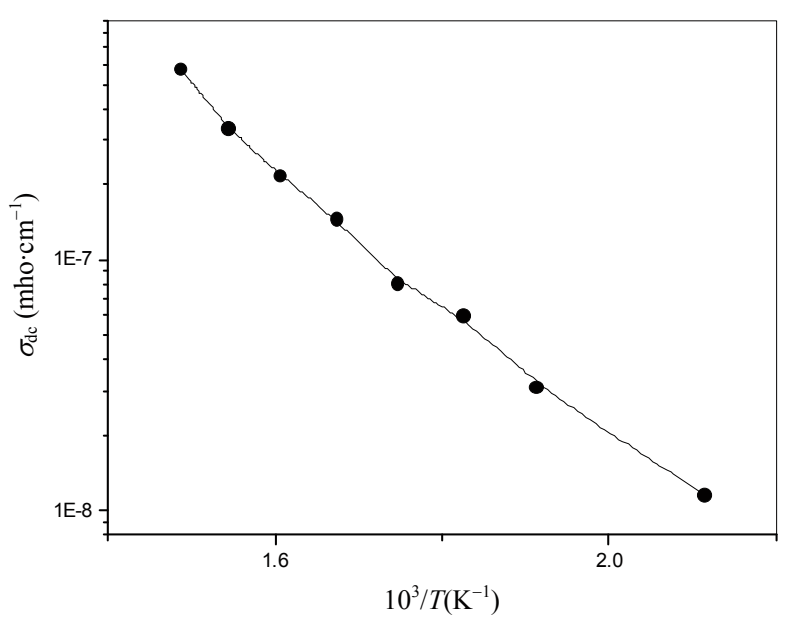

Fig. 9 Variation of dc conductivity with inverse of absolute temperature.

conductivity increases with rise in temperature confirming the presence of negative temperature co-efficient of resistance (NTCR) behavior in the material. This plot follows the Arrhenius relation: $\sigma_{\mathrm{dc}}=\sigma_{o} \mathrm{e}^{-\frac{E_{\mathrm{a}}}{K_{\mathrm{B}} T}}$. The activation energy value estimated from the plot was found to be $1.53 \mathrm{eV}$ which quite different from the value estimated from the relaxation time plot. This implies that the charge carriers responsible for conduction and relaxation processes are different $[16,23]$.

\subsection{3 ac conductivity}

The temperature dependence of ac conductivity $\left(\sigma_{\mathrm{ac}}\right)$ at 10 and $100 \mathrm{kHz}$ is shown in Fig. 10. The value of $\sigma_{\mathrm{ac}}$ is calculated from the dielectric data using the relation: $\sigma_{\mathrm{ac}}=\omega \varepsilon_{\mathrm{r}} \varepsilon_{0} \tan \delta$, where $\varepsilon_{0}$ is the vacuum dielectric constant and $\omega$ is the angular frequency. The nature of variation of $\sigma_{\mathrm{ac}}$ over a wide temperature range supports

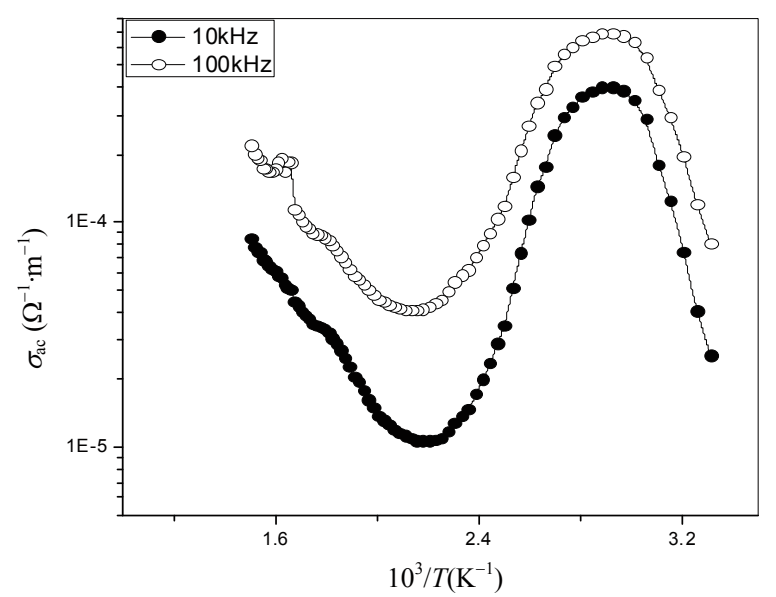

Fig. 10 Variation of ac conductivity with inverse of absolute temperature at different frequencies. the thermally activated transport properties of the material obeying Arrhenius equation: $\sigma_{\mathrm{ac}}=\sigma_{o} \mathrm{e}^{-\frac{E_{\mathrm{a}}}{K_{\mathrm{B}} T}}$, where the symbols have their usual meanings. The anomaly in slope of ac conductivity of the sample at $342 \mathrm{~K}$ corresponds to the anomaly observed in our dielectric study. The ac conductivity pattern indicates a progressive rise with temperature having maximum enhancement in at higher frequencies. The $E_{\mathrm{a}}$ of the sample is found to be $0.65 \mathrm{eV}$ in the ferroelectric phase $\left(<T_{\mathrm{c}}\right)$ and $0.49 \mathrm{eV}$ in the para electric phase $\left(>T_{\mathrm{c}}\right)$ for $10 \mathrm{kHz}$. Similarly, for $100 \mathrm{kHz} E_{\mathrm{a}}$ is $0.44 \mathrm{eV}\left(<T_{\mathrm{c}}\right)$ and $0.39 \mathrm{eV}\left(>T_{\mathrm{c}}\right)$ respectively. Above $T_{\mathrm{c}}$, there is an abrupt change in the slope of Arrhenius plot along with change in $E_{\mathrm{a}}$. This is associated with the oxygen ion vacancies (i.e., space charge) that are created due to the variable valence state of Tantalum (i.e., $\mathrm{Ta}^{4+}-\mathrm{Ta}^{5+}$ ) at higher temperature, which contributes to the conduction process. The reason for higher value of $E_{\mathrm{a}}$ in the paraelectric region is that, the donors create a level in the vicinity of conduction band and also due to the presence of oxygen ion vacancies in the sample. So, the conductivity may be of mixed type (i.e., ionicpolaronic and space charge) [51-52].

The frequency dependence of ac conductivity at various temperatures is shown in Fig. 11. At low temperatures the conductivity increases with increase in frequency which is a characteristic of $\omega^{n}(n=$ exponential). At higher temperatures, frequency independent ac conductivity is observed in the low frequency region. This frequency independent region increases with increase in temperature and obeys the phenomenological law (Jonscher's universal power law): $\sigma_{\mathrm{ac}}=\sigma_{\mathrm{dc}}+A \omega^{n}$ [38], where $\sigma_{\mathrm{dc}}$ is the frequency

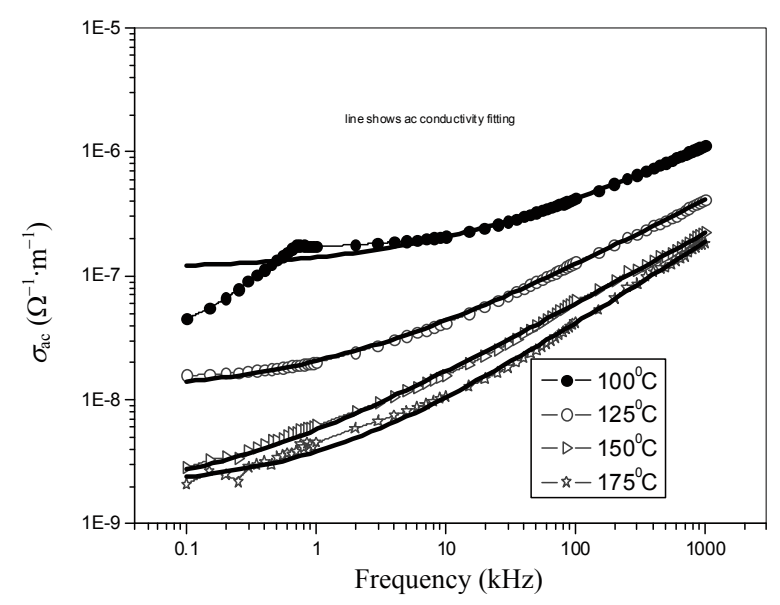

Fig. 11 Variation of ac conductivity with frequency at different temperatures. 
independent term giving dc conductivity, the exponent $\mathrm{n}$ (which generally varies between 0 to 1 ) represents the degree of interaction between mobile ions with the lattices around them, and $A$ determines the strength of polarizability. The parameter $n$ is frequency independent but temperature and material dependent [53]. The continuous solid line (in Fig. 11) represents the fitted curve (i.e., fitted with Jonscher's power law). A close agreement between the experimental data and the fitted data is observed. The values of $\mathrm{dc}$ conductivity, A and $\mathrm{n}$ are compared in Table 1. From the table it is clear that the dc conductivity increases with rise in temperature (as expected) in the given material.

Table 1 Comparison of $\sigma_{\mathrm{dc}}, A$ and $n$ at different temperatures

\begin{tabular}{cccc}
\hline Temperature $\left({ }^{\circ} \mathrm{C}\right)$ & $\sigma_{\mathrm{dc}}\left(\mathrm{ohm}^{-1} \mathrm{~m}^{-1}\right)$ & $A$ & $n$ \\
\hline 100 & 0.00011 & $8.25 \times 10^{-7}$ & 0.514 \\
125 & 0.00001 & $2.13 \times 10^{-7}$ & 0.545 \\
150 & $1.6697 \mathrm{E}-6$ & $7.58 \times 10^{-8}$ & 0.576 \\
175 & $2.0025 \mathrm{E}-6$ & $1.80 \times 10^{-8}$ & 0.668 \\
\hline
\end{tabular}

\section{Conclusion}

The polycrystalline sample of $\mathrm{Na}_{2} \mathrm{~Pb}_{2} \mathrm{La}_{2} \mathrm{~W}_{2} \mathrm{Ti}_{4} \mathrm{Ta}_{4} \mathrm{O}_{30}$, synthesized by a high-temperature solid-state reaction technique, has orthorhombic structure at room temperature. The compound shows diffuse-type of ferroelectric phase transition with transition temperature $\left(T_{\mathrm{c}}\right)$ well above the room temperature. The Nyquist plots confirmed the contributions of grain and grain boundary effect to the conductivity of the material. Studies of electrical conductivity (both dc and ac) over a wide temperature range suggest that the material exhibits the NTCR behavior and obeys Joncher's power law.

\section{References}

[1] Neurgaonkar RR, Nelson JG, Oliver JR, et al. Ferroelectric and structural properties of the tungsten bronze system $\mathrm{K}_{2} \mathrm{Ln}^{3+} \mathrm{Nb}_{5} \mathrm{O}_{15}, \mathrm{Ln}=\mathrm{La}$ to $\mathrm{Lu}$. Ma Res Bull 1990, 25: 959-970.

[2] Neurgaonkar RR, Cory WK, Ratnakar R. Progress in photorefractive tungstenbronze crystals. $J$ Opt Soc Am B 1986, 3: 274-282.

[3] Wakiya N, Wang JK, Saiki A, et al. Synthesis and dielectric properties of $\mathrm{Ba}_{1-x} \mathrm{R}_{2 \times / 3} \mathrm{Nb}_{2} \mathrm{O}_{6}$ (R: rare earth) with tetragonal tungsten bronze structure. $J$ Eur Ceram Soc 1999, 19: 1071-1075.

[4] Goodman G. Ferroelectric properties of lead metaniobate. J Am Ceram Soc 1953, 36: 368-372.

[5] Francombe MH, Lewis B. Structural, dielectric and optical properties of ferroelectric lead metaniobate. Acta Crystallogr 1958, 11: 696-703.

[6] Smolenskii GA, Agranovskaya AI. Doklady Akademii Nauk SSSR 1954, 97: 237.

[7] Glass AM. Ferroelectric $\mathrm{Sr}_{1-x} \mathrm{Ba}_{x} \mathrm{Nb}_{2} \mathrm{O}_{6}$ As a fast and sensitive detector of infrared radiation. Appl Phys Lett 1968, 13: 147-149.

[8] Sakamoto S, Yazaki T. Anomalous electro-optic properties of ferroelectric strontium barium niobate and device applications. Appl Phys Lett 1973, 22: 429-431.

[9] Haussonne JM, Desgardin G, Herve A, et al. Dielectric ceramics with relaxors and a tetragonal tungsten bronze. J Eur Ceram Soc 1992, 10: 437-452.

[10] Alaoui-Belghiti H El, Von der Miihll R, Simon A, et al. Relaxor or classical ferroelectric behavior in ceramics with composition $\mathrm{Sr}_{2-x} \mathrm{~A}_{1+x} \mathrm{Nb}_{5} \mathrm{O}_{15-x} \mathrm{~F}_{x}(\mathrm{~A}=$ $\mathrm{Na}, \mathrm{K})$. Mater Lett 2002, 55: 138-144.

[11] Chen XM, Xu ZY, Li J. Dielectric ceramics in $\mathrm{BaO}-\mathrm{Sm}_{2} \mathrm{O}_{3}-\mathrm{TiO}_{2}-\mathrm{Ta}_{2} \mathrm{O}_{5}$ quaternary system. $J$ Mater Res 2000, 15: 125-129.

[12] Das PR, Biswal L, Parida BN, et al. Diffuse ferroelectric phase transition in $\mathrm{Na}_{2} \mathrm{~Pb}_{2} \mathrm{Pr}_{2} \mathrm{~W}_{2} \mathrm{Ti}_{4} \mathrm{Nb}_{4} \mathrm{O}_{30}$ ceramic. Int $J$ Mat Sc 2010, 5: 759-767.

[13] Das PR, Behera S, Nayak P. Structural and ferroelectric properties of

[14] $\mathrm{Na}_{2} \mathrm{~Pb}_{2} \mathrm{Nd}_{2} \mathrm{~W}_{2} \mathrm{Ti}_{4} \mathrm{Ta}_{4} \mathrm{O}_{30}$ ceramic. AIP Conf Proc 2011, 1372: 33-40.

[15] Das PR, Behera S, Nayak P. Structural and dielectric properties of $\mathrm{Na}_{2} \mathrm{~Pb}_{2} \mathrm{Sm}_{2} \mathrm{~W}_{2} \mathrm{Ti}_{4} \mathrm{Ta}_{4} \mathrm{O}_{30}$ ferroelectric ceramics. Int J Mat Sc 2010, 5: 739-746.

[16] Pradhan DK, Behera B, Das PR. Studies of dielectric and electrical properties of a new type of complex tungsten bronze electro ceramics. J Mater Sci: Mater Electron 2012, 23: 779-785.

[17] Parida BN, Das PR, Padhee R, et al. A new ferroelectric oxide $\mathrm{Li}_{2} \mathrm{~Pb}_{2} \mathrm{Pr}_{2} \mathrm{~W}_{2} \mathrm{Ti}_{4} \mathrm{Nb}_{4} \mathrm{O}_{30}$ : Synthesis and characterization, $J$ Phys Chem Solids 2012, 73: 713-719.

[18] Das Piyush R, Pati B , Sutar BC, et al. Electrical properties of complex tungsten bronze ferroelectrics: $\mathrm{Na}_{2} \mathrm{~Pb}_{2} \mathrm{R}_{2} \mathrm{~W}_{2} \mathrm{Ti}_{4} \mathrm{~V}_{4} \mathrm{O}_{30}(\mathrm{R}=\mathrm{Gd}, \mathrm{Eu})$. Adv Mat Lett 2012, 3: 8-14.

[19] Parida BN, Das Piyush R, Padhee R, et al. Synthesis and chracterization of a tungsten bronze ferroelectric oxide. Adv Mat Lett 2012, 3: 231-238.

[20] Lines ME, Glass AM. Principle and Applications of 
Ferroelectrics and Related Materials. Oxford: Clarndon Press, 1977.

[21] Das PR , Biswal L, Behera B, et al. Structural and electrical properties of $\mathrm{Na}_{2} \mathrm{~Pb}_{2} \mathrm{Eu}_{2} \mathrm{~W}_{2} \mathrm{Ti}_{4} \mathrm{X}_{4} \mathrm{O}_{30}(\mathrm{X}=$ $\mathrm{Nb}, \mathrm{Ta})$ ferroelectric ceramics. Mater Res Bull 2009, 44: 1214-1218.

[22] Massarotti V, Capsoni D, Bini M, et al. Structural and spectroscopic properties of pure and doped $\mathrm{Ba}_{6} \mathrm{Ti}_{2} \mathrm{Nb}_{8} \mathrm{O}_{30}$ tungsten bronze. J Phys Chem B 2006, 110: $17798-17805$.

[23] Ganguly P, Jha AK, Deori KL. Complex impedance studies of tungsten-bronze structured $\mathrm{Ba}_{5} \mathrm{SmTi}_{3} \mathrm{Nb}_{7} \mathrm{O}_{30}$ ferroelectric ceramics. Solid State Comm 2008, 146: 472-477.

[24] Das Piyush R, Choudhary RNP, Samantray BK. Diffuse ferroelectric phase transition in $\mathrm{Na}_{2} \mathrm{~Pb}_{2} \mathrm{Sm}_{2} \mathrm{~W}_{2} \mathrm{Ti}_{4} \mathrm{Nb}_{4} \mathrm{O}_{30}$ ceramics. Mat Chem Phy 2007, 101: 228-233.

[25] Das Piyush R, Behera B, Choudhary RNP, et al. Ferroelectric properties of $\mathrm{Na}_{2} \mathrm{~Pb}_{2} \mathrm{R}_{2} \mathrm{~W}_{2} \mathrm{Ti}_{4} \mathrm{~V}_{4} \mathrm{O}_{30}(\mathrm{R}=$ Dy, Pr) ceramics. Res Lett Mat Sci 2007, ID: 91796.

[26] Behera B, Nayak P, Choudhary RNP. Structural, dielectric and electrical properties of $\mathrm{LiBa}_{2} \mathrm{X}_{5} \mathrm{O}_{15}(X=$ $\mathrm{Nb}$ and $\mathrm{Ta}$ ) ceramics. Mat Chem Phys 2006, 100: 138-141.

[27] Das Piyush R, Choudhary RNP, Samantray BK. Diffuse phase transition in $\mathrm{Na}_{2} \mathrm{~Pb}_{2} \mathrm{R}_{2} \mathrm{~W}_{2} \mathrm{Ti}_{4} \mathrm{~V}_{4} \mathrm{O}_{30}$ ( $R=\mathrm{Gd}, \mathrm{Eu})$ ferroelectric ceramics. $J$ Phys Chem Solids 2007, 68: 516-522.

[28] Behera B, Nayak P, Choudhary RNP. Studies of dielectric and impedance properties of $\mathrm{KCa}_{2} \mathrm{~V}_{5} \mathrm{O}_{15}$ ceramics. J Phys Chem Solids 2008, 69: 1990-1995.

[29] $\mathrm{Wu}$ PE. An interactive powder diffraction data interpretation and indexing Program, Ver. 2.5, School of Physical Sciences, Finders University of South Australia Bedford Park, S.A. 5042, Australia.

[30] Anderson JC. Dielectrics. London: Chapman and Hall, 1964.

[31] Padhee R, Das PR, Parida BN, et al. Structural, dielectric and electrical properties of dysprosium based new complex electro ceramics. J Mat Sci: Mater Electron 2012, 23: 1688-1697.

[32] Pilgrim SM, Sutherland AE, Winzer SR. Diffuseness as a useful parameter for relaxor ceramics. J Amer Ceram Soc 1990, 73: 3122-3125.

[33] Clarke R, Burfoot JC. The diffuse phase transition in potassium strontium niobate. Ferroelectrics 1974, 8: 505-506.

[34] Suman CK, Prasad K, Choudhary RNP. Complex impedance studies on tungsten-bronze electro ceramic: $\mathrm{Pb}_{2} \mathrm{Bi}_{3} \mathrm{LaTi}_{5} \mathrm{O}_{18}$. J Mater Sci 2006, 41: 369-375.

[35] Suman CK, Prasad K, Choudhary RNP. Electrical properties of $\mathrm{Pb}_{2} \mathrm{Bi}_{3} \mathrm{NdTi}_{5} \mathrm{O}_{18}$ ceramic. Mat Chem Phys 2003, 82: 140-144.

[36] Kroger FA, Vink HJ. Relations between the concentrations of imperfections in crystalline. Solids Solid State Phys 1956, 3: 307-435.

[37] Raghavan V. Materials Science and Engineering. New Delhi: Prentice-Hall of India, 2004.

[38] Macdonald JR. Impedance Spectroscopy. New York: Wiley, 1987.

[39] Jonscher AK. The 'universal' dielectric response. Nature 1977, 267: 673-679.

[40] Sen S, Choudhary RNP. Impedance studies of $\mathrm{Sr}$ modified $\mathrm{BaZr}_{0.05} \mathrm{Ti}_{0.95} \mathrm{O}_{3}$ ceramics. Mater Chem Phys 2004, 87: 256-263.

[41] Kim JS, Kim JN. Impedance spectra near the phase transition temperature of potassium lithium niobate crystals. Jpn J Appl Phys 2000, 39: 3502-3505.

[42] Lu Z, Bonnet JP, Ravez J, et al. An impedance study of $\mathrm{Pb}_{2} \mathrm{KNb}_{5} \mathrm{O}_{15}$ ferroelectric ceramics. Phys Chem Solids 1992, 53: 1-9.

[43] Jonscher AK. Dielectric Relaxation in Solids. London: Chelesa Dielectric Press, 1983.

[44] Dissado LA, Hill RH. Non-exponential decay in dielectrics and dynamics of correlated systems. Nature 1979, 279: 685-689.

[45] Dissado LA, Hill RM. Dielectric behaviour of materials undergoing dipole alignment transitions. Phill Mag B 1980, 41: 625-642.

[46] Yeum B. Z SimpWin Version 2.00, Echem Software Ann Arbor, MI, USA.

[47] Irvine TS, Sinclair DC, West AR. Electroceramics: Characterization by impedance spectroscopy. $A d v$ Mater 1990, 2: 132-138.

[48] Nobre MAL, Lanfredi S. Ferroelectric state analysis in grain boundary of $\mathrm{Na}_{0.85} \mathrm{Li}_{0.15} \mathrm{NbO}_{3}$ ceramic. $J$ Appl Phy 2003, 93: 5557-5562.

[49] Macdonald JR. Note on the parameterization of the constant-phase admittance element. Solid state Ionics 1984, 13: 47-149.

[50] West AR, Sinclair DC, Hirose N. Characterization of electrical materials, especially ferroelectrics, by impedance spectroscopy. J Electro Ceram 1997, 1: 65-71.

[51] Choudhary RNP, Pradhan DK, Tirado CM, et al. Effect of La-substitution on structural and electrical properties of $\mathrm{Ba}\left(\mathrm{Fe}_{2 / 3} \mathrm{~W}_{1 / 3}\right) \mathrm{O}_{3}$ nanoceramics. J Mater Sci 2007, 42: 7423-7432.

[52] Deng G, Li G, Ding A, et al. Evidence for oxygen vacancy inducing spontaneous normal-relaxor transition in complex perovskite ferroelectrics. Appl Phys Lett 2005, 87: 192905-192908.

[53] Molak A, Talik E, Kruczek M, et al. Characterisation of $\mathrm{Pb}\left(\mathrm{Mn}_{1 / 3} \mathrm{Nb}_{2 / 3}\right) \mathrm{O}_{3}$ ceramics by SEM, XRD, XPS and dielectric permittivity tests. Mater Sci Eng B 2006, 128: 16-24.

[54] Jonscher AK. Dielectric Relaxation in Solids. London: Chelsea Dielectric Press, 1983. 